\title{
Gradation of Nanostructures in Cold-Rolled and Annealed Ti-Ni Shape Memory Alloys
}

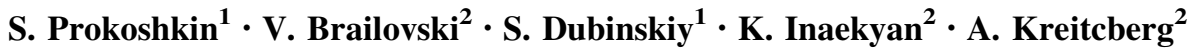

Published online: 22 February 2016

(C) ASM International 2016

\begin{abstract}
Nanostructures formed in Ti-50.26 at.\%Ni shape memory alloy as a result of post-deformation annealing (PDA) at $400{ }^{\circ} \mathrm{C}(1 \mathrm{~h})$ after cold rolling (CR) in the $e=0.3-1.9$ true strain range are classified and quantitatively studied. The statistical quantitative transmission electron microscopy analysis of bright and dark field images and selected area diffraction patterns reveal the following regularities. Two types of nanostructure form in B2-austenite as a result of PDA after CR: (a) a nanosubgrained structure, which consists of subgrains formed as a result of polygonization of the initially highly dislocated substructure; (b) a nanocrystalline structure, which represents a combination of the deformation-induced nanograins grown during PDA and new nano-grains formed during crystallization of the amorphous phase. After moderate $\mathrm{CR}(e=0.3)$, mainly nanosubgrained structure forms as a result of PDA. After CR of moderate-to-high intensity ( $e=0.5-1.0)$ followed by PDA, the structure is mixed (nanosubgrained+nanocrystalline). After high-intensity CR ( $e=1.2-1.9)$ and PDA, the structure is mainly nanocrystalline. This nanostructure identification allows adequate analysis of the nature of the parent phase boundaries in the thermomechanically processed $\mathrm{Ti}-\mathrm{Ni}$ alloys and of their effect on the transformation and mechanical behaviors.
\end{abstract}

S. Prokoshkin

prokoshkin@tmo.misis.ru

1 National University of Science and Technology "MISIS", 4, Leninskiy Prosp., Moscow, Russia 119049

2 Ecole de Technologie Superieure, 1100, Notre-Dame Street West, Montreal, H3C 1K3, Canada
Keywords Shape memory $\cdot \mathrm{NiTi} \cdot$ Nanostructured materials $\cdot$ Thermomechanical processing $\cdot$ Transmission electron microscopy $\cdot$ Structure parameters

\section{Introduction}

It was clearly shown that the mechanical and functional properties of metals nanostructured using the severe plastic deformation approach are significantly higher than those of their micro- and submicro-grained counterparts $[1,2]$. The same trend was also observed in $\mathrm{Ti}-\mathrm{Ni}$ shape memory alloys where different nanostructures can be created in high-temperature B2-austenite phase as a result of postdeformation annealing (PDA) after severe deformation by high-pressure torsion [3-7], cold rolling (CR) [8-13], and cold drawing [14-16] techniques.

The structure formation features observed by transmission electron microscopy in cold-rolled and then annealed $\mathrm{Ti}-\mathrm{Ni}$ alloys can be classified as a function of deformation intensity [11-13, 17]. In the range of moderate true strains (up to $e=0.3$ ), a well-developed dislocation substructure forms. In the $e=0.5-1.2$ strain range, this dislocation substructure is gradually replaced by a mixed amorphous and nanocrystalline structure, and when $e \geq 1.2$, the structure is mainly amorphous. Similar trends are observed in the case of $\mathrm{Ti}-\mathrm{Ni}$ alloys subjected to high-pressure torsion.

Note however that remnants of nanocrystalline structure are still present in the cold-rolled alloys after the highest applied strains of $e=2$. In the high-pressure torsion-processed alloys, areas containing highly dislocated substructure and nanocrystalline structure are still observable after $e \sim 3, \sim 10$, and even $e \geq 10$ [5, 6, 18, 19], the latter possibly being a result of the cyclic amorphization- 
crystallization phenomena accompanying severe plastic deformation [20, 21].

During PDA, the above-mentioned structures undergo specific structural changes: in the highly dislocated substructure, recovery, polygonization (which includes subgrain formation and growth), and finally recrystallization occur; the grains of the deformation-induced nanocrystalline structure grow, the amorphous phase crystallizes, and the crystallized nano-sized grains grow alongside their deformation-induced counterparts [11-13, 15-17]. Note that individual groups of nano-sized subgrains can still be found in the latter case [5].

The observed nanostructure gradation into "nanograins" and "nano-subgrains" is based on the well-understood difference between the nature of grains and subgrains: the term "grain" implies structure elements surrounded by high-angle boundaries (the misorientation angle $>15^{\circ}$ ), whereas the term "subgrain" implies structure elements surrounded by low-angle dislocation boundaries, or subboundaries. The nature of the parent phase boundaries is an essential factor affecting the transformation and mechanical behavior of shape memory alloys. The lowangle boundaries (i.e., subgrain boundaries, subboundaries) are directly inherited by growing martensite crystals and serve as partially permeable barriers for dislocation slip, while high-angle boundaries (grain boundaries) are non-permeable barriers for both the martensite crystals and dislocations [22]. As concerned with the functional properties, an outstanding combination of high recovery stress and completely recoverable strain can be obtained in the case of B2-austenite structure consisting of nano-sized grains [11, 12, 17], while the best functional fatigue properties can be observed in the case of a mixed B2austenite structure containing nano-sized grains and nanosized subgrains [17]. The nanostructure containing exclusively nano-sized subgrains exhibits the lowest performance from the static and fatigue functional properties points of view [11, 12, 17].

Even though the described structure changes in deformed and annealed Ti-Ni alloys are obvious and logical, some discrepancies exist in their interpretation. For example, the term "nano-grain", rather than the more accurate "nano-subgrain", is frequently used when describing all nano-sized structure elements formed during PDA of Ti-Ni alloys after low-to-moderate deformation $(e \approx 0.5)[10,23,24]$, or even structures directly resulting from cold deformation of moderate intensity [24]. The same misleading appellation is also frequently used to describe the martensitic transformation features in nanostructured Ti-Ni alloys [25, 26].

The objective of this work is to illustrate, by means of quantitative transmission electron microscopy study, the difference in nanostructure types formed in $\mathrm{Ti}-\mathrm{Ni}$ shape memory alloys subjected to CR and PDA and to determine the initial CR strain range for transition from one type to another.

\section{Experimental}

The Ti-50.26 at.\%Ni alloy wire samples were homogenized at $700{ }^{\circ} \mathrm{C}(1 \mathrm{~h})$, water-cooled, and thermomechanically treated: 0.9 and 2.5 -mm-diameter wires (the latter only in the case of $e=0.3$ ) were cold-rolled in several passes with a logarithmic strain ranging from $e=0.3-1.9$. The samples of the deformed material were then annealed at $400{ }^{\circ} \mathrm{C}(1 \mathrm{~h})$, and water-cooled to room temperature. Thin foils for electron microscopy study were prepared by electrolytical thinning of cut samples in $\mathrm{HClO}_{4}$ and $\mathrm{CH}_{3}$ $\mathrm{COOH}$ solutions.

The following structure parameters taken from bright field (BF) and dark field (DF) images and selected area electron diffraction patterns (SAEDPs) were treated, using the statistical metallography procedures, to collect the following quantitative data:

- BF images the average grain/subgrain size $(A S)$ obtained by measuring an average distance between boundaries/subboundaries; i.e., any boundary is taken into consideration.

- DF images (1) the visible surface areas occupied by nano-sized subgrains $\left(F_{\text {NSS }}\right)$ (not to be confused with their volume fractions), and (2) the average size of the individual regions occupied by the nano-sized subgrains $\left(L_{\mathrm{NSS}}\right)$. The DF images were taken in each case from the most intensive part of the diffraction ring or arc.

- SAEDP the fraction of various types of SAEDP: $N_{\mathrm{I}}$ (mainly nano-sized subgrains), $N_{\mathrm{II}}$ (nano-sized subgrains and grains), and $N_{\text {III }}$ (mainly nano-sized grains). To ensure more representative statistics, the SAEDPs produced in this study were completed by the SAEDPs obtained in our earlier works on binary $\mathrm{Ti}-\mathrm{Ni}$ alloys of different compositions but subjected to identical thermomechanical treatments. This methodology is deemed adequate since SAEDPs keep their particular features up to the recrystallization temperature, the latter occurring in this alloy in the $450-550{ }^{\circ} \mathrm{C}$ temperature range, depending on the alloy's composition and thermomechanical history $[11,12,27]$. The selected area diameter was $1 \mu \mathrm{m}$.

The histograms of the $A S$ and $L_{\mathrm{NSS}}$ distributions were built using the linear intercept method: 508-542 linear intercepts for $A S$ and $60-127$ linear intercepts for $L_{\mathrm{NSS}}$, both in the 5-10 random independent fields range per treatment. As for $F_{\mathrm{NSS}}$, it was calculated using the point- 

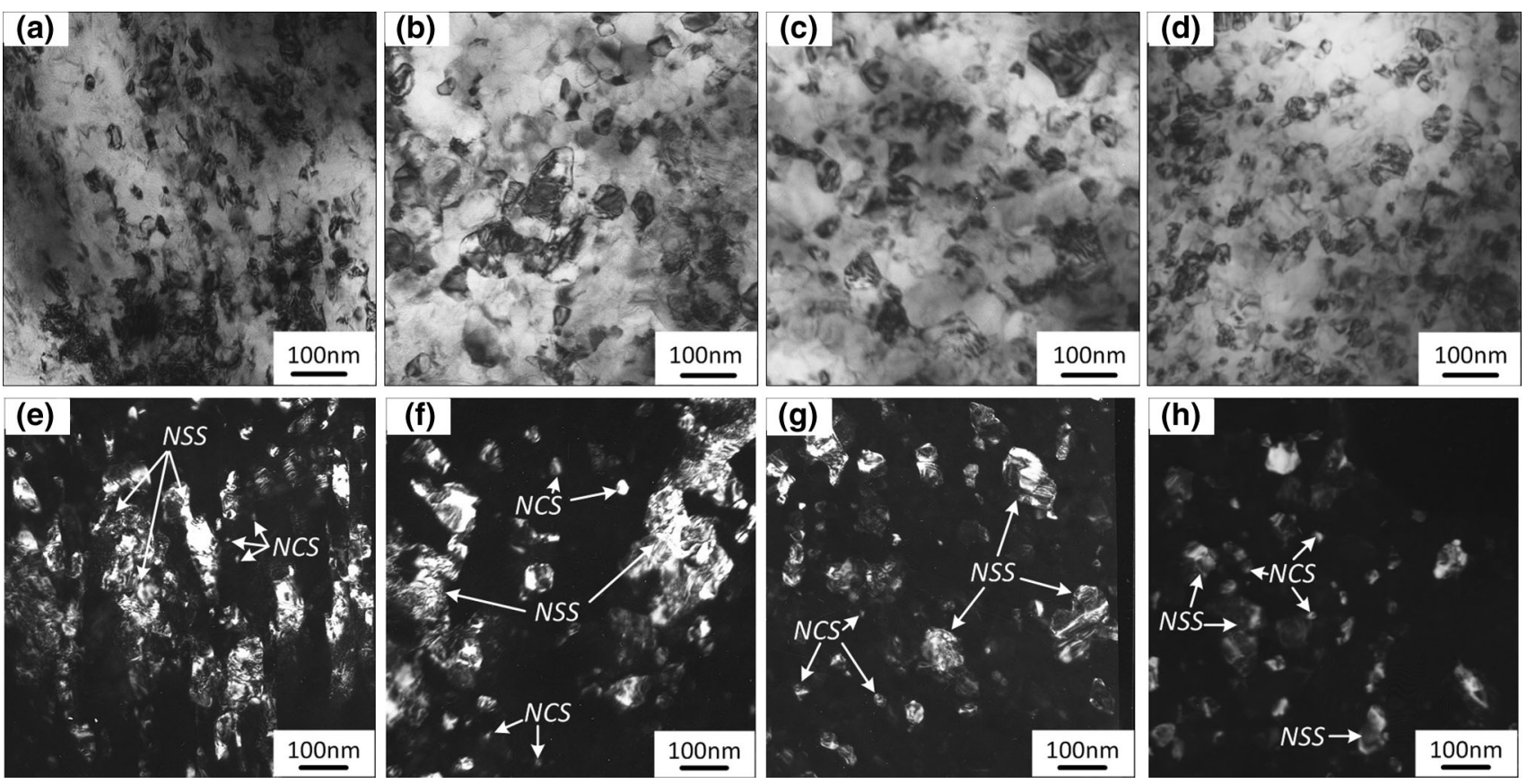

Fig. 1 Typical nanostructures in cold-rolled and annealed at $400{ }^{\circ} \mathrm{C}(1 \mathrm{~h}) \mathrm{Ti}-50.26$ at.\%Ni alloy. Initial CR strain: a, e $e=0.3$; b, f $0.75 ; \mathbf{c}$, g 1.5; d, h 1.9. a-d bright field, $\mathbf{e}-\mathbf{h}$ dark field images

counting method with $2251-2844$ points in the 8-13 random independent fields range per treatment. From the histograms, the average parameter value and its confidence interval with a $95 \%$ probability were calculated. The $N_{\mathrm{I}}$, $N_{\text {II }}$, and $N_{\text {III }}$ fractions were determined by a direct classification of 11-22 SAEDPs per treatment.

\section{Results and Discussion}

To perform this study, the CR strain range of $e=0.3-1.9$ is chosen to cover a large spectrum of deformation-induced structures: from the highly dislocated substructure to the mixed amorphous and nanocrystalline structure. The PDA temperature of $400{ }^{\circ} \mathrm{C}$ is then selected to ensure the best direct visibility of nanostructure elements. Note that the structures formed as a result of such a PDA allow an unambiguous assessment of the preceding deformationinduced structure formation processes. Indeed, the nanosized subgrains form as a result of polygonization of a highly dislocated substructure resulting from the low-tomoderate deformation intensities, whereas the nano-sized grains are the result of two simultaneous processes: crystallization of the amorphized material and growth of the deformation-refined nano-sized grains.

The main phase under consideration is B2-austenite. Other phases, which can simultaneously be observed at room temperature, either inherit B2-austenite substructure and misorientations (B19' and R martensites) or affect its transformation kinetics upon cooling and heating $\left(\mathrm{Ti}_{3} \mathrm{Ni}_{4}\right.$ phase).

Before presentation and discussion of the results, an important terminological assumption is proposed. Since a clear source of the discrepancies in the nanostructure elements interpretation is the plural meaning of the commonly used term "nanocrystalline structure" or NCS, we propose to reserve this term to designate nano-sized grain structure only, while applying different term, "nanosubgrained structure" or NSS, to designate nano-sized subgrain substructure. (Moreover, if the size of the regions consisting of nano-subgrains exceeds $100 \mathrm{~nm}$ [13, 28], these regions should be regarded as submicrocrystalline.)

The results of the statistical investigation of the nanostructure parameters are considered below in the following sequence: BF image, then DF image, and finally, SAEDP parameters.

The typical BF nanostructure images are presented in Fig. 1a-d. It can be seen that the nanostructures observed after different CR strains, but subjected to identical annealing conditions, are visually hardly distinguishable on these images. Only in the case of the lowest initial CR strain, $e=0.3$ (Fig. 1a), the regions with high dislocation density are observed more frequently, and, sometimes, they look like regions of an incompletely recovered dislocation substructure. In other words, one cannot conclude on whether these are grains (high-angle grain boundaries) or subgrains (low-angle subboundaries). The only conclusion that can be drawn from the results of the statistical analysis 
Fig. 2 SAEDP types in nanostructured $\mathrm{Ti}-\mathrm{Ni}$ alloys: a, b Type I; c, d Type II; e, f Type III (see detailed description in the text). Examples of typical $\mathrm{B} 2, \mathrm{R}$ and $\mathrm{B} 19^{\prime}$ reflections are indicated by arrows. A set of overlapping arc reflections embraced by the square bracket in (b) consists of $110_{\mathrm{B} 19^{\prime}}$, $002_{\mathrm{B} 19^{\prime}}, 11 \overline{1}_{\mathrm{B} 19^{\prime}}, 330_{\mathrm{R}}, 110_{\mathrm{B} 2}$, $330_{\mathrm{R}}, 020_{\mathrm{B} 19^{\prime}}, 111_{\mathrm{B} 19^{\prime}}$, sequentially
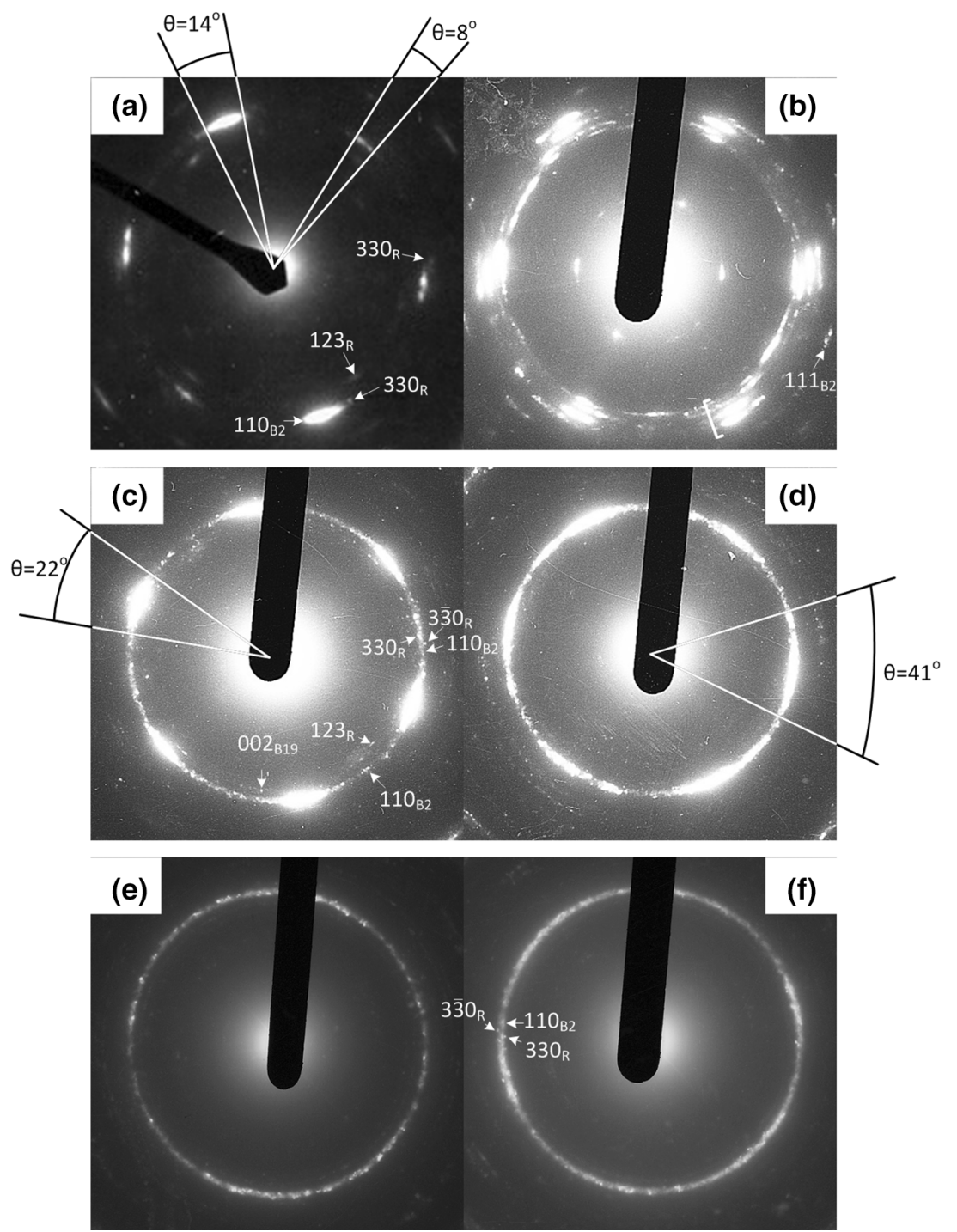

presented in Fig. 3a is that when CR strain increases from 0.3 to 1.0 , the grain/subgrain size decreases from $\sim 45$ to $\sim 35 \mathrm{~nm}$ gradually and becomes stable at higher strains.

Typical DF nanostructure images are presented in Fig. 1e-h. Two types of bright structure elements are observable there: (1) individual grain-like elements which do not border on other bright elements and (2) bright regions which themselves represent a group of many (at least, two) neighboring grain-like structure elements. In accordance with the definitions given above, the first type of the DF image-observed features should be considered as grains, and the structure consisting of such grains described as NCS. Conversely, the second type of the DF imagefeatures should be considered as regions containing closely oriented nano-sized subgrains (a polygonized, or subgrained, dislocation substructure, or NSS).

The examples of DF images of $\mathrm{Ti}-50.26 \% \mathrm{Ni}$ alloy annealed at $400{ }^{\circ} \mathrm{C}(1 \mathrm{~h})$ after $\mathrm{CR}(e=0.3-1.9)$ are presented in Fig. 1e-h to illustrate a gradual replacement of NSS by NCS with increasing CR strain. This visual impression is confirmed by the results of the statistical analysis of the DF images in Fig. $3 b$ and showing a significant decrease in the NSS area fraction when CR strain increases from 0.3 to 1.9. This replacement of NSS by NCS is accompanied by a permanent decrease in the average size of NSS regions which transits from a submicro- to a nanoscale range (Fig. 3c). The subgrain and grain sizes were not measured from the DF images because not all the subboundaries and grain boundaries were clearly visible. The following important observation should be emphasized: NSS does not vanish even when the highest CR strain of $e=1.9$ is applied, whereas the NCS is already observable even for the lowest CR strain of $e=0.3$.

The main types of SAEDPs are presented in Fig. 2. These three SAEDP types are characterized as follows: 


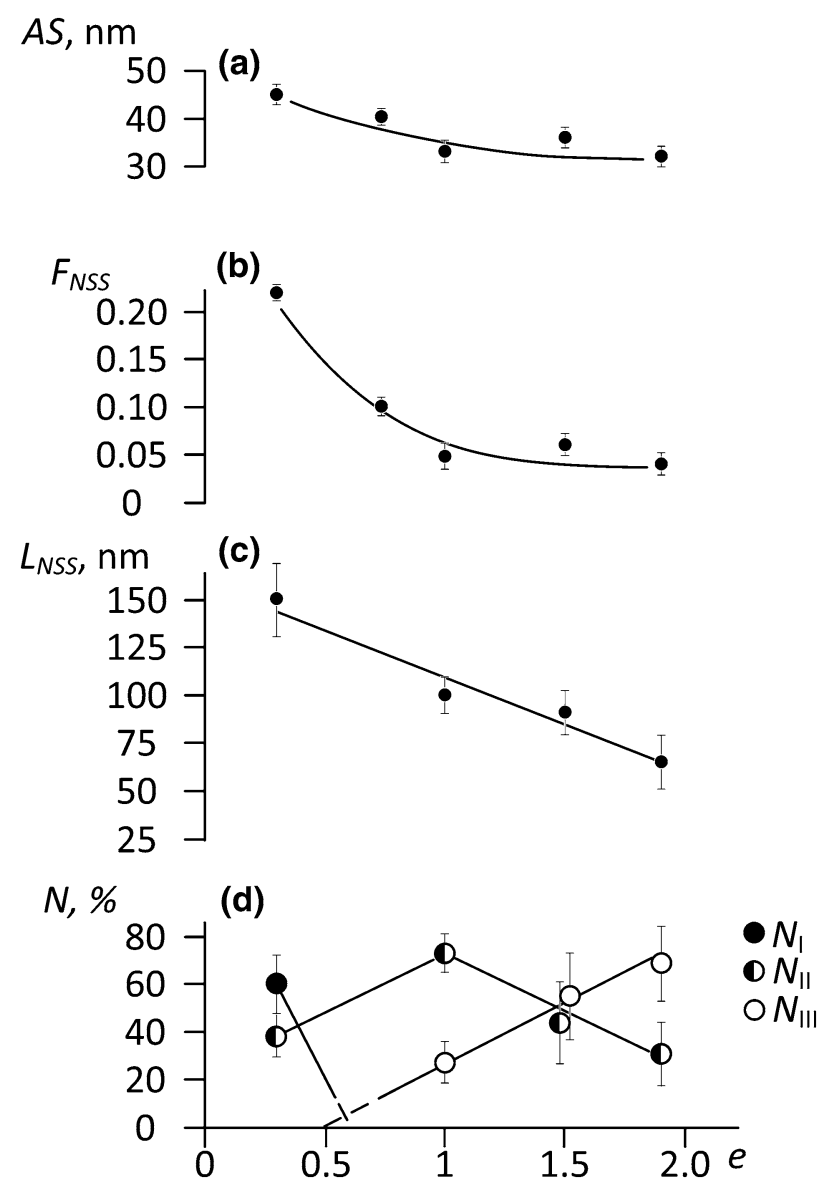

Fig. 3 Nanostructure parameters after PDA versus initial CR strain: a average subgrain/grain size in BF images (AS), $\mathbf{b}$ visible fraction of DF image area occupied by NSS ( $\left.F_{\mathrm{NSS}}\right)$, $\mathbf{c}$ average size of NSS region evaluated from DF images $\left(L_{\mathrm{NSS}}\right)$, $\mathbf{d}$ fraction of a given SAEDP type (N). a-c for Ti-50.26\% Ni alloy after PDA at $400{ }^{\circ} \mathrm{C}(1 \mathrm{~h})$; d summarized data for Ti-50.26\% Ni alloy after PDA at $400{ }^{\circ} \mathrm{C}$ (1 h), and Ti-50.0 and Ti-50.7\% Ni alloys after PDA at $200-450{ }^{\circ} \mathrm{C}$, $1 \mathrm{~h})$. Combined data for $e=0.75$ and 1.0 are shown in $\mathbf{d}$ at $e=1.0$, and for $e=1.2$ and 1.5 in $\mathbf{d}$ at $e=1.5$

Type I (Fig. 2a, b): arc-shaped fragmented or nonfragmented B2-phase reflections with low-angle $\left(<15^{\circ}\right)$ azimuthal broadening (mainly NSS). These reflections can be accompanied by rare individual B2-phase point reflections from NCS distributed along a ring (Fig. 2b). Reflections of other phases $\left(\mathrm{R}, \mathrm{B} 19^{\prime}\right)$, which preserve an orientation relationship with $\mathrm{B} 2$-austenite, possess the same shape.

Type II (Fig. 2c, d): arc-shaped intensive B2-phase reflections with high-angle $\left(>15^{\circ}\right)$ azimuthal broadening superposed on point reflections scattered along a ring (mixed NSS+NCS). Note that the arc-shaped reflections observed in this study, as well as in many other studies, indicate a rolling texture, which is $\{111\}_{\mathrm{B} 2}$ in most cases. However, it should be emphasized that a decision on the nature of the related reflecting structure elements, whether they are grains or subgrains, can be taken only after examination of the corresponding DF images.

Type III (Fig. 2e, f): more or less uniform point ring (mainly NCS).

The examples of SAEDPs of Ti-50.26 at.\%Ni alloy annealed at $400{ }^{\circ} \mathrm{C}(1 \mathrm{~h})$ after $\mathrm{CR}$ strain ranging from $e=0.3-1.9$ illustrate a continuous transition from NSS to NCS when CR strain increases (Fig. 2b-f). The SAEDPs presented in Fig. $2 b-d, f$ correspond to the areas shown in Fig. 1a-d, respectively. Figure 2a presents Type I SAEDP free of the superposed B19'-martensite reflections (it belongs to equiatomic Ti-Ni alloy annealed at $300{ }^{\circ} \mathrm{C}(1 \mathrm{~h})$ after $\mathrm{CR}(e=0.3)[11])$.

The mentioned regularity follows from the results of the statistical analysis of the SAEDPs presented in Fig. 3d, which clearly shows a transition from the SAEDP Type I through the SAEDP Type II to the SAEDP Type III, with CR strain increasing from 0.3 to 1.9 .

The parallel analysis of the BF, DF, and SAEDP images allows us to confirm that the structures, resulting either from cold deformation of Ti-Ni SMA with low-to-moderate strains $(0.3-0.5)$ or obtained during annealing after such deformations, cannot be regarded as truly nanocrystalline, i.e., consisting of nano-sized grains exclusively. If they are considered directly after deformation, these structures represent a mixture of highly dislocated, nanocrystalline and amorphized regions. When they are observed after PDA, these structures represent a mixture of nanosubgrained and nanocrystalline structures. (The latter definition is only valid if the annealing temperature is low enough to avoid recrystallization or growth of the nanosized grains and subgrains beyond the nanometric scale.)

\section{Conclusions}

In conclusion, the results of the statistical analysis unambiguously indicate that

(1) There are two types of nanostructures formed in $\mathrm{Ti}-$ Ni shape memory alloys as a result of PDA after cold deformation: (a) a nanosubgrained structure which consists of closely oriented subgrains separated by low-angle dislocation boundaries (subboundaries) formed as a result of polygonization of the initially highly dislocated substructure; (b) a nanocrystalline structure, which consists of grains separated by highangle boundaries (grain boundaries) formed as a result of growth of the deformation-induced nanograins and of the nano-grains formed as a result of crystallization of the amorphous phase.

(2) The formation of specific nanostructures during PDA depends on the initial cold work intensity (case of 
$\mathrm{CR}$ ): when $\mathrm{CR}$ logarithmic thickness reduction increases from $e=0.3$ to 1.9 , the nanosubgrained structure gradually transforms to the nanocrystalline structure. After $\mathrm{CR}$ of low-to-moderate intensity $(e=0.3, \ldots, 0.5)$, the structure is mainly nanosubgrained. After $\mathrm{CR}$ of moderate-to-high intensity $(e=0.5, \ldots, 1.0)$, the structure is mixed (nanosubgrained+nanocrystalline). Finally, after high-intensity, or severe, $\mathrm{CR}(e=1, \ldots, 2)$, the structure is mainly nanocrystalline.

(3) The PDA after CR in the applied CR strain range does not result in the formation of "pure" nanosubgrained or nanocrystalline structures. Traces of the nanocrystalline structure are already observed for the true strains as low as $e=0.3$, whereas traces of the nanosubgrained structure are still present for the true strains as high as $e=2$.

Acknowledgments The present work was carried out with the financial support of the Natural Science and Engineering Research Council of Canada and the Ministry of Education and Science of the Russian Federation in the framework of the Increase Competitiveness Program of NUST"MISIS" (Grant No. K4-2014-018) and State Task No. 16.1790.2014K of the Ministry of Education and Science of the Russian Federation.

\section{References}

1. Valiev RZ, Islamgaliev RK, Alexandrov IV (2000) Bulk nanostructured materials from severe plastic deformation. Prog Mater Sci 45:103-189

2. Valiev R (2002) Materials science: nanomaterial advantage. Nature 419:887-889

3. Tatyanin EV, Kurdyumov VG, Fedorov VB (1986) Production of amorphous $\mathrm{Ti}-\mathrm{Ni}$ alloys by shear deformation under pressure. Phys Metals Metallogr 62:133-137

4. Sergueeva AV, Song C, Valiev RZ et al (2003) Structure and properties of amorphous and nanocrystalline NiTi prepared by severe plastic deformation and annealing. Mater Sci Eng A 339:159-165

5. Brailovski V, Khmelevskaya IY, Prokoshkin SD et al (2004) Foundation of heat and thermomechanical treatments and their effect on the structure and properties of titanium nickelide-based alloys. Phys Metals Metallogr 97(Suppl. 1):S3-S55

6. Waitz T, Kazykhanov V, Karnthaler HP (2004) Martensitic phase transformations in nanocrystalline NiTi studied by TEM. Acta Mater 52:137-147

7. Prokoshkin SD, Khmelevskaya IY, Dobatkin SV et al (2005) Alloy composition, deformation temperature, pressure and postdeformation annealing effects in severely deformed Ti-Ni based shape memory alloys. Acta Mater 53:2703-2714

8. Fedorov VB, Kurdyumov VG, Khakimova DK, Tatyanin EV (1983) Dispersion effect upon plastic deformation of titanium nickelide. Dokl Akad Nauk SSSR 269:885-888

9. Nakayama H, Tsuchiya K, Umemoto M (2001) Crystal refinement and amorphization by cold rolling in TiNi shape memory alloys. Scr Mater 44:1781-1785

10. Kim Y, Cho G, Hur S et al (2006) Nanocrystallization of a Ti$50.0 \mathrm{Ni}$ (at.\%) alloy by cold working and stress-strain behavior. Mater Sci Eng A 438-440:531-535
11. Brailovski V, Prokoshkin SD, Khmelevskaya IY et al (2006) Structure and properties of the Ti-50.0at\% Ni alloy after strain hardening and nanocrystallizing thermomechanical processing. Mater Trans 47:795-804

12. Prokoshkin SD, Brailovski V, Inaekyan KE et al (2008) Structure and properties of severely cold-rolled and annealed Ti-Ni shape memory alloys. Mater Sci Eng A 481-482:114-118

13. Prokoshkin SD, Brailovski V, Korotitskiy AV et al (2010) Specific features of the formation of the microstructure of titanium nickelide upon thermomechanical treatment including cold plastic deformation to degrees from moderate to severe. Phys Met Metallogr 110:289-303

14. Tsuchiya K, Hada Y, Koyano T et al (2009) Production of TiNi amorphous/nanocrystalline wire with high strength and elastic modulus by severe cold drawing. Scr Mater 60:749-752

15. Delville R, Malard B, Pilch J et al (2010) Microstructure changes during non-conventional heat treatment of thin $\mathrm{Ni}-\mathrm{Ti}$ wires by pulsed electric current studied by transmission electron microscopy. Acta Mater 58:4503-4515

16. Malard B, Pilch J, Sittner P et al (2011) In situ investigation of the fast microstructure evolution during electropulse treatment of cold drawn NiTi wires. Acta Mater 59:1542-1556

17. Brailovski V, Prokoshkin S, Inaekyan K et al (2011) Functional properties of nanocrystalline, submicrocrystalline and polygonized Ti-Ni alloys. J Alloys Compd 509:2066-2075

18. Rentenberger C, Waitz T, Karnthaler HP (2004) HRTEM analysis of nanostructured alloys processed by severe plastic deformation. Scr Mater 51:789-794

19. Peterlechner M, Bokeloh J, Wilde G, Waitz T (2010) Study of relaxation and crystallization kinetics of NiTi made amorphous by repeated cold rolling. Acta Mater 58:6637-6648

20. Sundeev RV, Glezer AM, Shalimova AV (2014) Structural and phase transitions in the amorphous and nanocrystalline $\mathrm{Ti}_{50}$ $\mathrm{Ni}_{25} \mathrm{Cu}_{25}$ alloys upon high-pressure torsion. Mater Lett 133:32-34

21. Glezer AM, Sundeev RV (2015) General view of severe plastic deformation in solid state. Mater Lett 139:455-457

22. Bernshtein ML, Kaputkina LM, Prokoshkin SD (1979) The inheritance of lattice defects during $\gamma \Leftrightarrow \alpha$ transformation and martensite structure in thermomechanically treated steel. In: Proceedings of international conference ICOMAT, Cambridge, p $118-123$

23. Tsuchiya K, Inuzuka M, Tomus D et al (2006) Martensitic transformation in nanostructured $\mathrm{TiNi}$ shape memory alloy formed via severe plastic deformation. Mater Sci Eng A 438-440:643-648

24. Ahadi A, Sun Q (2013) Stress hysteresis and temperature dependence of phase transition stress in nanostructured $\mathrm{NiTi}-$ effects of grain size. Appl Phys Lett 103(021902):1-5

25. Ahadi A, Sun Q (2014) Effects of grain size on the rate-dependent thermomechanical responses of nanostructured superelastic NiTi. Acta Mater 76:186-197

26. Ahadi A, Sun Q (2015) Stress-induced nanoscale phase transition in superelastic NiTi by in situ X-ray diffraction. Acta Mater 90:272-281

27. Prokoshkin SD, Khmelevskaya IY, Brailovski V et al (2003) Comparative study of structure and strain diagram changes in Ti$\mathrm{Ni}$ alloys thermomechanically treated in martensitic and austenitic states. J de Phys IV 112:651-654

28. Kreitcberg A, Brailovski V, Prokoshkin S, Inaekyan K (2014) Influence of thermomechanical treatment on structure and processing-induced crack propagation in nanostructured $\mathrm{Ti}$ 50.26at\%Ni alloy. Metallogr Microstr Anal 3:46-57 